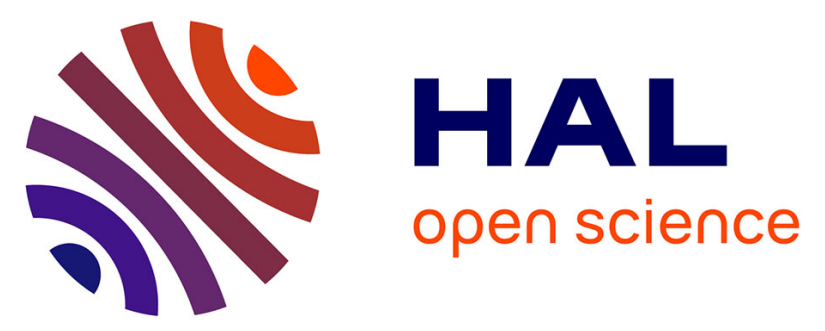

\title{
Analytical performances of laser-induced micro-plasma of Al samples with single and double ultrashort pulses in air and with Ar-jet: A comparative study
}

A. Semerok, Christophe Dutouquet

\section{- To cite this version:}

A. Semerok, Christophe Dutouquet. Analytical performances of laser-induced micro-plasma of Al samples with single and double ultrashort pulses in air and with Ar-jet: A comparative study. Spectrochimica Acta Part B: Atomic Spectroscopy, 2014, 99, pp.163-171. 10.1016/j.sab.2014.06.022 . ineris-01862453

HAL Id: ineris-01862453

https://hal-ineris.archives-ouvertes.fr/ineris-01862453

Submitted on 27 Aug 2018

HAL is a multi-disciplinary open access archive for the deposit and dissemination of scientific research documents, whether they are published or not. The documents may come from teaching and research institutions in France or abroad, or from public or private research centers.
L'archive ouverte pluridisciplinaire HAL, est destinée au dépôt et à la diffusion de documents scientifiques de niveau recherche, publiés ou non, émanant des établissements d'enseignement et de recherche français ou étrangers, des laboratoires publics ou privés. 


\title{
Analytical performances of micro-LIBS of Al samples with single and double ultrashort pulses in air and with Ar-jet: a comparative study
}
A. Semerok ${ }^{1}$ and C. Dutouquet ${ }^{1,2}$

\author{
${ }^{1}$ CEA Saclay, DEN/DPC/SEARS/LISL, 91191 Gif-sur-Yvette, France \\ ${ }^{2}$ INERIS/DRC/CARA/NOVA, F-60550 Verneuil En Halatte, France
}

\begin{abstract}
.
Ultrashort pulse laser microablation coupled with optical emission spectroscopy was under study to obtain several micro-LIBS analytical features (shot-to-shot reproducibility, spectral line intensity and lifetime, calibration curves, detection limits). Laser microablation of $\mathrm{Al}$ matrix samples with known $\mathrm{Cu}$ - and $\mathrm{Mg}$-concentrations was performed by single and double pulses of $50 \mathrm{fs}$ and 1 ps pulse duration in air and with Ar-jet.

The micro-LIBS analytical features obtained under different experimental conditions were characterized and compared. The highest shot-to-shot reproducibility and gain in plasma spectral line intensity were obtained with double pulses with Ar-jet for both 50 fs and 1 ps pulse durations. The best calibration curves were obtained with $1 \mathrm{ps}$ pulse duration with Ar-jet. MicroLIBS with ultrashort double pulses may find its effective application for surface elemental microcartography.
\end{abstract}




\section{Introduction}

Laser microablation coupled with optical emission spectroscopy (micro-LIBS) for elemental surface cartography and microanalysis of solid samples was under study in [1-7]. With micro-LIBS applying ns laser pulse durations, the surface analysis was provided with a spatial resolution of the order of some micrometers [4]. Microablation with ultrashort laser pulses (fs and ps) has demonstrated the improved analytical performances (depth and lateral resolution, ablation efficiency) along with a higher accuracy of matter sampling and reduced thermal damage of the target surface [8-14].

The principal physical mechanisms of laser pulse interaction with solid/ablated matter and of laser plasma formation are quite different for laser ablation with fs and ns pulse durations [15]. With fs pulses (when pulse duration is shorter than electron-phonon relaxation time), the pulse energy is completely deposited into the sample long before the matter ejection takes place. In this case, a more reproducible ablation without shielding of the sample surface by laser plasma may be expected. However, as there is no laser beam/plasma plume interaction, one faces a problem of short-lived analytical plasma and, as a result, a LIBS signal of a low intensity.

In search for the ways for laser plasma "reheating" in microablation with ultrashort pulses, laser ablation of metal samples was performed with double pulses (50 fs - 10 ps pulse duration and interpulse time delay $\Delta \mathrm{t}_{\mathbf{1 2}}=50 \mathrm{fs}-250 \mathrm{ps}$ ) in [16-18]. Application of femtosecond double pulses with the appropriate interpulse time delay $\Delta \mathbf{t}_{\mathbf{1 2}}$ has resulted in significant increase in intensity and reproducibility of the optical emission signal from the laser plasma plume [1617]. The measurements of crater depths and volumes revealed that with double pulses (50 fs -1 ps), the second pulse was no longer affecting the target surface for the interpulse time delay $\Delta \mathbf{t}_{\mathbf{1 2}}$ $>10 \mathrm{ps}$. Thus, a time delay $\Delta \mathbf{t}_{\mathbf{1 2}}>10 \mathrm{ps}$ was the optimal one for plasma "reheating". With $50 \mathrm{fs}$ pulses, the total plasma intensity with double pulses of $20 \mu \mathrm{J}(2 \times 20 \mu \mathrm{J})$ was 100 times higher than the one with a single pulse of the same pulse energy $(1 \times 20 \mu \mathrm{J})$, and 50 times higher than the one with a single pulse but with a doubled pulse energy $(1 \times 40 \mu \mathrm{J})$. Our observations on ultrashort double pulse ablation have been confirmed in similar studies in [19-36].

In this study, $\mathrm{Al}$ matrix samples with different $\mathrm{Cu}$ - and $\mathrm{Mg}$-concentrations were under ultrashort laser microablation (50 fs and 1ps, $40-2 \times 200 \mu \mathrm{J}$, single and double pulses, in air and with Ar-jet) to obtain several micro-LIBS analytical features (signal reproducibility, spectral line intensity gain and emission lifetime, calibration curve, detection limit). The results of this study are compared with those obtained in our earlier investigations [16-17] and also in [19-36]. The conclusions on possible improvements of several analytical features of micro-LIBS are made. 


\section{Experimental setup and parameters}

\subsection{Experimental setup}

The general diagram of the experimental setup is presented in Figure 1. A home-made femtosecond laser system "BOOSTER/LUCA" (CEA Saclay, DSM/IRAMIS/SPAM) was developed and applied for microablation of $\mathrm{Al}$ matrix samples with different $\mathrm{Cu}$ - and $\mathrm{Mg}$ concentration to obtain several analytical features of the micro-LIBS signal. The setup provided ultrashort pulses $\left(\mathrm{TEM}_{\mathrm{oo}}\right.$ mode, $20 \mathrm{~Hz}$ repetition rate frequency, $800 \mathrm{~nm}$ wavelength, $50 \mathrm{fs}$ and 1 ps, $40-200 \mu \mathrm{J}$ per pulse, single and double pulses, in air and with Ar-jet).

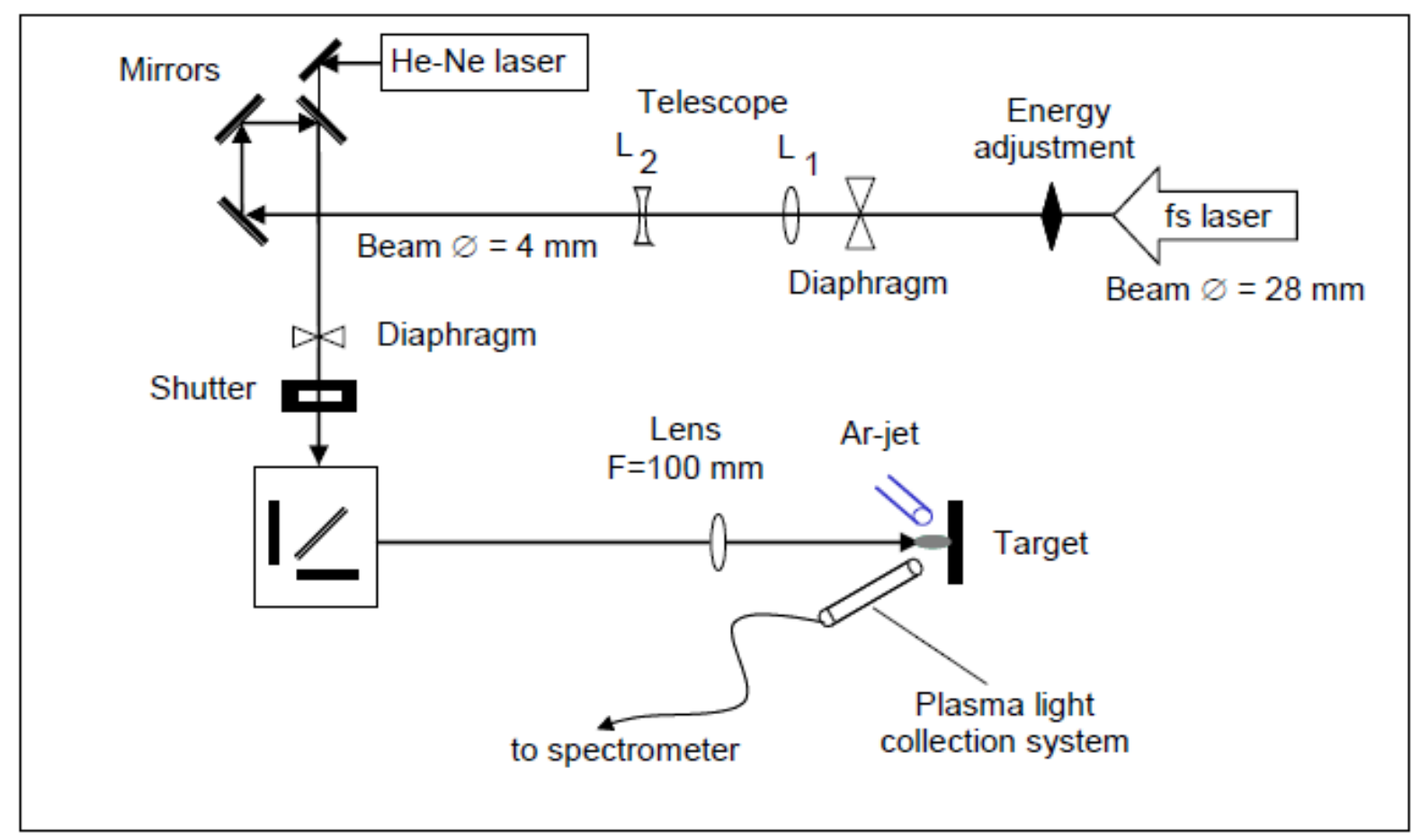

Figure 1. Diagram of the experimental setup for micro-LIBS measurements.

A telescope with $\mathrm{L}_{1}$ and $\mathrm{L}_{2}$ lenses (1000 $\mathrm{mm}$ and $250 \mathrm{~mm}$ focal length, respectively) was used to reduce the initial beam diameter from $28 \mathrm{~mm}$ (on 1/e) to $4 \mathrm{~mm}$, in order to make it compatible with the optical mirrors and mechanical shutter apertures. The laser beam energy was adjusted by $\lambda / 2$ and two Brewster plates. The energy of the laser beam was measured by a joule meter (Optilas RJP 435), while its spatial profile was measured by a Spiricon camera. The shutter control unit was used for shot-to-shot laser pulse application. Double pulses with the interpulse time delay $\left(\Delta \mathrm{t}_{12}=150 \mathrm{ps}\right)$ were provided by a Michelson interferometer. A $100 \mathrm{~mm}$ lens was used to focus the laser beam normally to the $\mathrm{Al}$ sample into a spot of $10 \mu \mathrm{m}$ diameter (1/e of the Gaussian intensity distribution). Special attention was paid to the target positioning (accuracy within $50 \mathrm{~nm}$ ) and precise laser beam focalization on the target surface. Laser beam focalization was controlled by recording the Al spectrum line intensity (on $\lambda=394.4 \mathrm{~nm}$ and $\lambda=396.152 \mathrm{~nm}$ ) 
of the $\mathrm{Al}$ samples under study. As the impurity concentration in all the samples was low (below $5 \%$ ), the $\mathrm{Al}$ spectrum line intensity was almost constant and was used as a reference to verify the optimal laser beam focusing.

The diagram of the optical setup for light collection emitted by the laser plasma plume is shown in Figure 2. An optical fiber (silica, $15 \mathrm{~m}$ length, $940 \mu \mathrm{m}$ core diameter, numerical aperture NA $=0.22$ ) was used for plasma light transportation. It is necessary to mention that the reproducibility of a LIBS-signal may be seriously affected by an excessive magnification of the plasma plume image onto the optical fiber input. Also, the instability of the plasma shape from shot to shot may result in deterioration of the analytical signal reproducibility. In this study, the magnification of the collection optics was under particular control. An optical objective (15 mm diameter, $25 \mathrm{~mm}$ focal length) was used to image the total volume of micro-plasma plume (typical size of $200 \mu \mathrm{m}$ ) onto the optical fiber entrance with a $2 \times$ magnification. A double-lens system was used for imaging the fiber output onto the spectrometer entrance slit without overtaking the spectrometer numerical aperture (NA). This, the maximal light collection was provided.

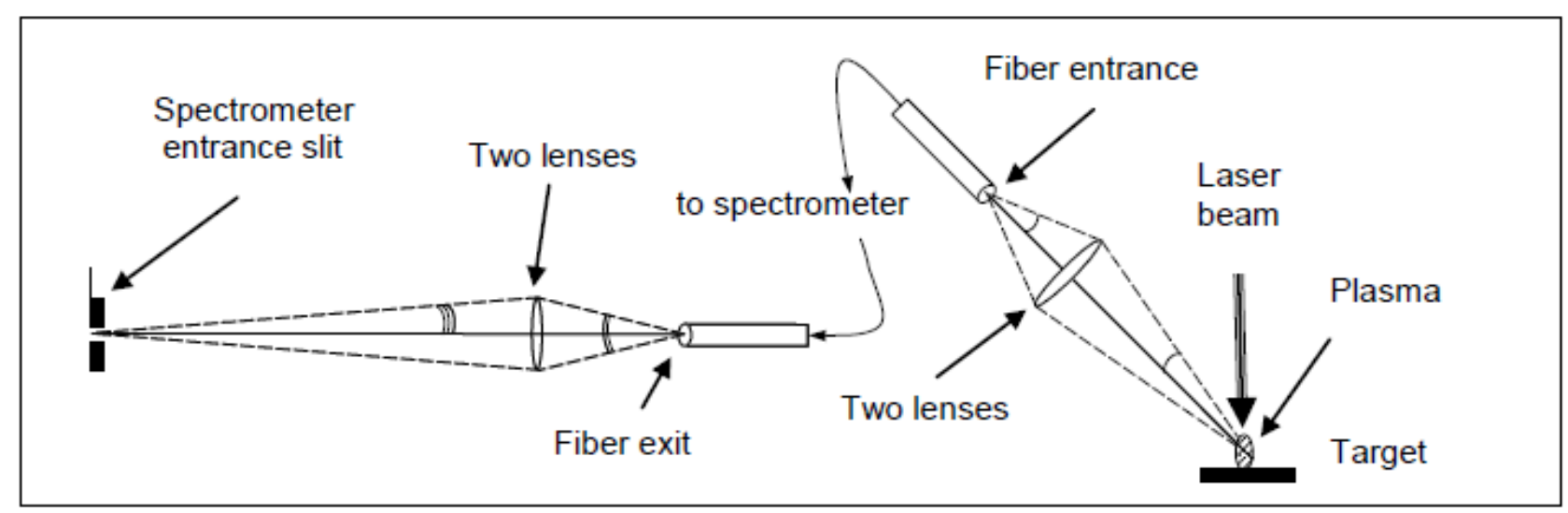

Figure 2. Diagram of the optical setup for light collection.

For spectroscopic measurements, we used a THR 1000 Czerny-Turner spectrometer ( $1 \mathrm{~m}$ focal distance, $1800 \mathrm{~mm}^{-1}$ grating, $\lambda / \Delta \lambda=2.3 \times 10^{4}$ spectral resolution, $\approx 5.5 \mathrm{~nm}$ spectral windows on $\lambda=632.8 \mathrm{~nm}, 140 \mathrm{~mm}$ mirrors dimensions, NA=0.07). The spectrometer was equipped with a Princeton ICCD camera (matrix of 576 x 384 pixels of $22.5 \mu \mathrm{m}$ size, 200-800 nm spectral sensitivity range, cooled by a Peltier module). The ICCD detector was shielded by a flow of dry nitrogen to avoid water condensation from air. The time delay and gate of the ICCD camera were adjusted by a pulse generator (PG 200 Princeton). 


\subsection{Samples and spectral line features}

One polished aluminum sample and two sets of $\mathrm{Al}$ matrix samples with $\mathrm{Cu}$ and $\mathrm{Mg}$ analytical elements ( $\mathrm{Al}-\mathrm{Cu}$ and $\mathrm{Al}-\mathrm{Mg}$ ) were under our experimental study. Table 1 presents different impurities and their mass content $(\%)$ in the polished $\mathrm{Al}$ matrix sample. In this paper, this sample is referred to as "the polished Al sample". Table 2 presents two sets of Al matrix samples (4 samples in each set) with different content (\%) of the analytical elements $\mathrm{Cu}$ and $\mathrm{Mg}$, referred to as (Cu-1, 2, 3, 4) and $(\mathrm{Mg}-1,2,3,4)$ samples, respectively.

Table 1. Impurity content (mass \%) in the polished Al matrix sample.

\begin{tabular}{|c|c|c|c|c|c|c|c|c|c|c|}
\hline Element & $\mathrm{Si}$ & $\mathrm{Fe}$ & $\mathrm{Cu}$ & $\mathrm{Mn}$ & $\mathrm{Mg}$ & $\mathrm{Cr}$ & $\mathrm{Ni}$ & $\mathrm{Zn}$ & $\mathrm{Ti}$ & $\mathrm{Pb}$ \\
\hline $\begin{array}{c}\text { Content } \\
(\mathrm{mass} \%)\end{array}$ & 0.57 & 0.6 & 3 & 0.29 & 1.5 & 0.1 & 0.05 & 0.18 & 0.095 & 0.25 \\
\hline
\end{tabular}

Table 2. Al matrix samples with different content (\%) of $\mathrm{Cu}$ - and $\mathrm{Mg}$-analytical element.

\begin{tabular}{|c|c|c|c|}
\hline $\begin{array}{c}\mathrm{Al}-\mathrm{Cu} \\
\text { samples }\end{array}$ & $\begin{array}{c}\mathrm{Cu} \text {-content } \\
(\text { mass \%) }\end{array}$ & $\begin{array}{c}\mathrm{Al}-\mathrm{Mg} \\
\text { samples }\end{array}$ & $\begin{array}{c}\mathrm{Mg} \text {-content } \\
(\text { mass \%) }\end{array}$ \\
\hline$(\mathrm{Cu}-1)$ & 4.3 & $(\mathrm{Mg}-1)$ & 4.9 \\
\hline$(\mathrm{Cu}-2)$ & 2.2 & $(\mathrm{Mg}-2)$ & 2.4 \\
\hline$(\mathrm{Cu}-3)$ & 0.89 & $(\mathrm{Mg}-3)$ & 1.1 \\
\hline$(\mathrm{Cu}-4)$ & 0.46 & $(\mathrm{Mg}-4)$ & 0.65 \\
\hline
\end{tabular}

A spectroscopic analysis of LIBS plasma under our experimental conditions did not reveal the excessive number of $\mathrm{Al}$ spectral lines, which could present a problem for the detection of the spectral lines for the impurities with a low concentration. Thus, the spectra of the elements with a low concentration did not interfere with $\mathrm{Al}-, \mathrm{Cu}$ - and $\mathrm{Mg}$-spectra in our measurements.

Table 3 presents the spectral line features of the target analytical elements (analytical transitions, spectral line wavelength $(\lambda)$ and probability $\left(A_{i j}\right)$ of analytical spectral line transitions from upper $\left(E_{i}\right)$ to lower $\left(E_{j}\right)$ energy levels) [19].

Table 3. Spectral line wavelength $(\lambda)$, probability $\left(A_{i j}\right)$ of analytical spectral line transition from upper $\left(E_{i}\right)$ to lower $\left(E_{j}\right)$ energy level for Al-, $\mathrm{Cu}$ - and Mg-analytical elements.

\begin{tabular}{|c|c|c|c|c|}
\hline Element & $\lambda(\mathrm{nm})$ & $\mathrm{E}_{\mathrm{i}}\left(\mathrm{cm}^{-1}\right)$ & $\mathrm{E}_{\mathrm{j}}\left(\mathrm{cm}^{-1}\right)$ & $\mathrm{A}_{\mathrm{ij}}\left(10^{8} \mathrm{~s}^{-1}\right)$ \\
\hline $\mathrm{Al}$ & 396.15 & 25348 & 112 & 0.982 \\
\hline $\mathrm{Al}$ & 394.40 & 25348 & 0 & 0.498 \\
\hline $\mathrm{Cu}$ & 521.82 & 49942 & 30784 & 0.75 \\
\hline $\mathrm{Mg}$ & 518.36 & 41197 & 21911 & 0.575 \\
\hline
\end{tabular}




\subsection{Spectrum recording settings}

The optimal spectrum recording parameters of the ICCD gated camera (time delay $t_{d}$ after the laser shot and gate width $t_{g}$ ) were determined by the time-dependence of the analytical spectral line signal. The latter is regarded as a peak intensity (or an integral intensity) of the detected spectral lines. To obtain a higher reproducibility of the analytical signal, we used the ratio of the spectral line intensity of the analytical element versus the background intensity.

The temporal evolution of the spectral line intensity of $\mathrm{Al}$ (on $\lambda=396.152 \mathrm{~nm}$ ) was registered by the ICCD camera with a short gate width $\mathrm{t}_{\mathrm{g}}=20 \mathrm{~ns}$ for different time delays $\mathrm{t}_{\mathrm{d}}$. The measurements were made after each laser shot applied for the sample microablation. The Al spectral line intensity (peak values) evolution and the Al spectral line width (FWHM) versus the time delay $t_{d}$ are shown in Figure 3 (a) and (b), respectively. The auto-absorption of the spectral line was not very pronounced, even for the Al-resonant transitions. 

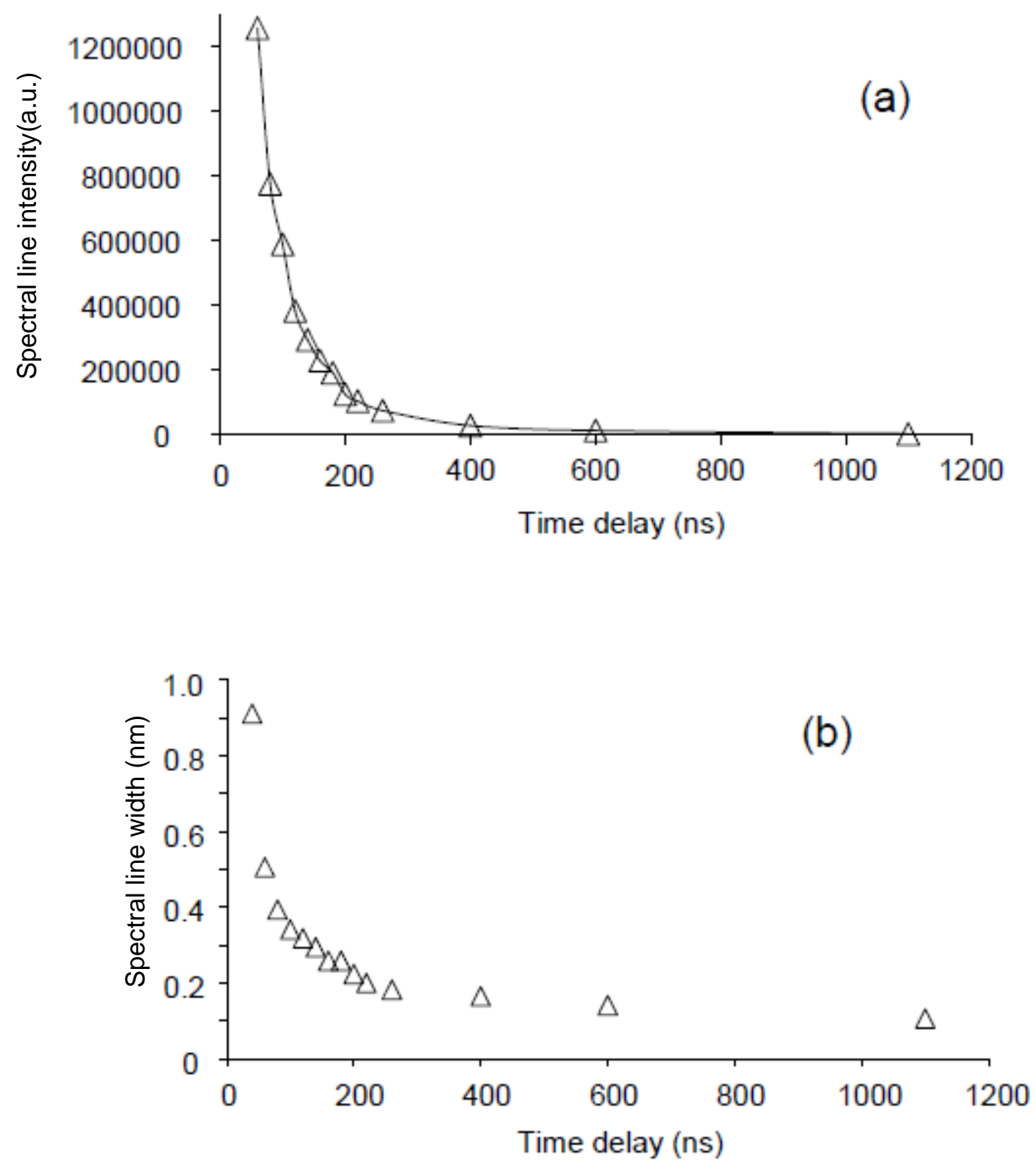

Figure 3. (a) - temporal evolution of Al spectral line intensity $(\lambda=396.15 \mathrm{~nm})$ in arbitrary units and (b) - spectral line width (FWHM) in nm versus the ICCD camera time delay for 50 fs microablation of the polished Al sample $\left(40 \mu \mathrm{J}\right.$, single pulse, in air, ICCD camera gate width $\mathrm{t}_{\mathrm{g}}=$ $20 \mathrm{~ns})$.

The above measurements were made with 30 accumulated spectra. A spectrum was registered after each laser shot using an optical spectrometer with a slit width of $300 \mu \mathrm{m}$, which corresponds to a $0.13 \mathrm{~nm}$ spectrometer resolution on $\lambda=518.36 \mathrm{~nm}$ ( $\mathrm{Mg}$ spectral line).

For $t_{d} \geq 150 \mathrm{~ns}$, the Al spectral line intensity was high enough. The line width was constant and not very wide for analytical applications, so as to ensure a better distinction of the 
registered spectra. The time delay $t_{d}=150 \mathrm{~ns}$ was regarded as the optimum. It was used throughout our study with the camera gate width $\mathrm{t}_{\mathrm{g}}=2 \mu \mathrm{s}$.

\section{EXPERIMENTS AND RESULTS}

\section{EXPERIMENTS AND RESULTS}

\subsection{Reproducibility of the LIBS-signal}

The polished Al sample was under microablation with ultrashort pulses (50 fs and $1 \mathrm{ps,}$ $40 \mu \mathrm{J}$ pulse energy, single and double pulses, in air and with Ar-jet). Thirty laser shots per crater were made to obtain several craters $(10 \mu \mathrm{m}$ diameter, $100 \mu \mathrm{m}$ apart on the target surface). The choice of this specific number of laser shots per crater was justified by the fact that the volume of ablated matter was in linear dependence with respect to the pulse number of up to 30 laser shots [17].

After each laser shot, the Al spectral line intensities (394.4 $\mathrm{nm}$ and $396.152 \mathrm{~nm}$ ) were recorded by the ICCD camera. Thus, 30 spectra per crater were registered (Figure 4). As the first laser shot was made to clean the target surface, the intensity of the very first spectrum line was lower than those of all the following spectra. Therefore, the first laser shot was not considered in $\mu$-LIBS signal reproducibility evaluation. Shot-to- shot signal reproducibility of the Al spectral line intensity with 50 fs double pulses both in air and with Ar-jet (Figures 4 b and 4c, respectively) was much better than the one with a single pulse in air (Figure 4 a). 

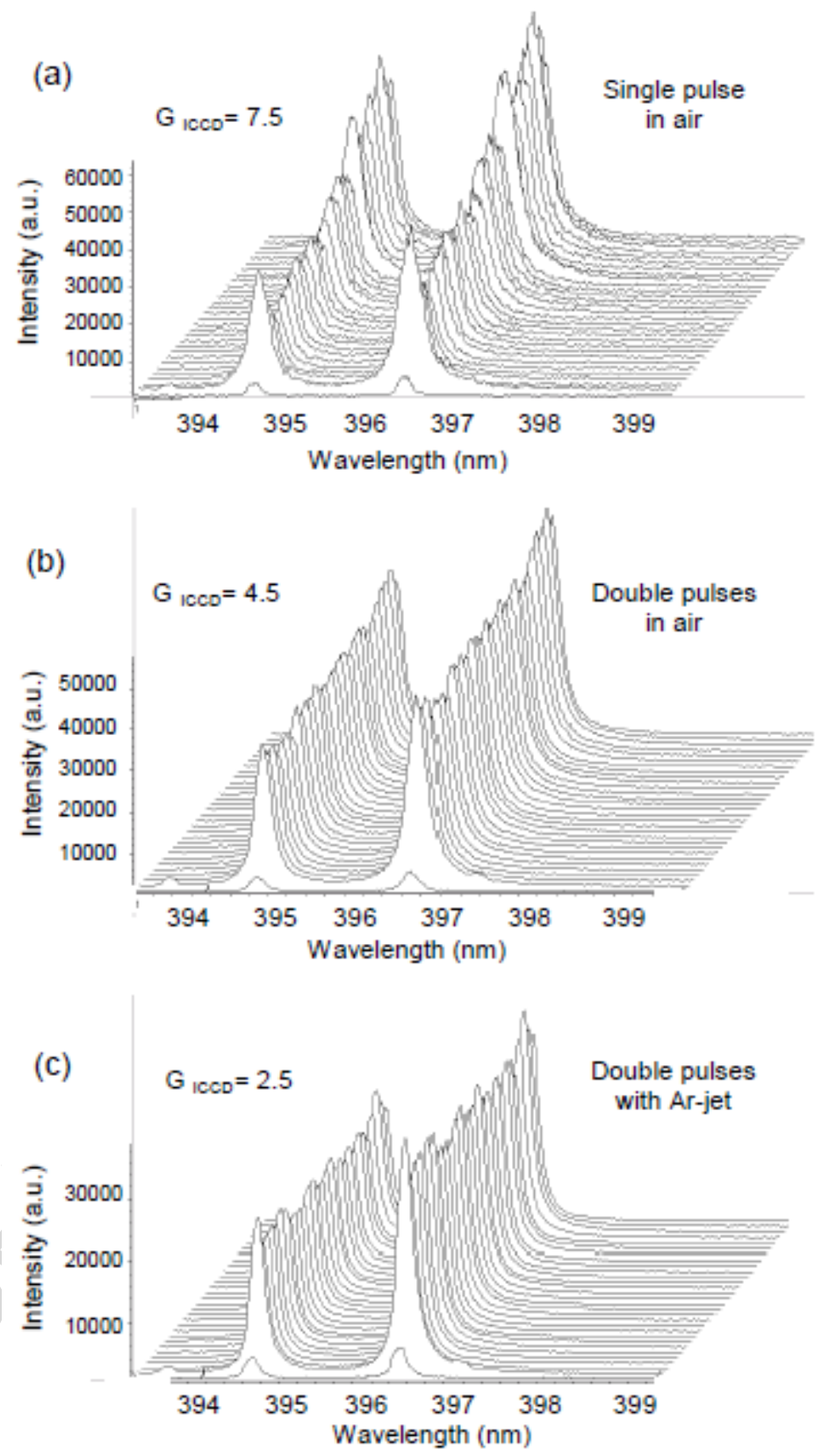

Figure 4. Thirty Al spectra $(\lambda=394.40 \mathrm{~nm}$ and $\lambda=396.15 \mathrm{~nm})$ for the polished $\mathrm{Al}$ sample under 50 fs microablation $(40 \mu \mathrm{J}, 30$ shots per crater): (a) - single pulse in air; (b) - double pulses in air; (c) - double pulses with Ar-jet. Al spectral line width (FWHM) is $0.26 \mathrm{~nm}(\lambda=396.15 \mathrm{~nm})$, spectrometer resolution is $0.1 \mathrm{~mm}$ for $300 \mu \mathrm{m}$ entrance slit width, ICCD camera delay $t_{d}=150$ ns and gate $t_{g}=2 \mu \mathrm{s}$. $\mathrm{G}_{\mathrm{ICCD}}$ - the applied ICCD camera gain.

The reproducibility of the Al line spectral intensity for both 50 fs and 1 ps pulses is shown in Figures 5a and 5b, respectively. With double pulses for both 50 fs and 1 ps (in air and with Ar-jet), the reproducibility of the signal intensity was very high $(\approx 10 \%)$, and much better than the one for single pulses under the same conditions (Figure 5). The spectral line intensity 
was almost constant for 30 laser shots on the same crater. However, it was observed to decrease for a larger number of laser shots per crater $(\approx 100$ shots $)$.
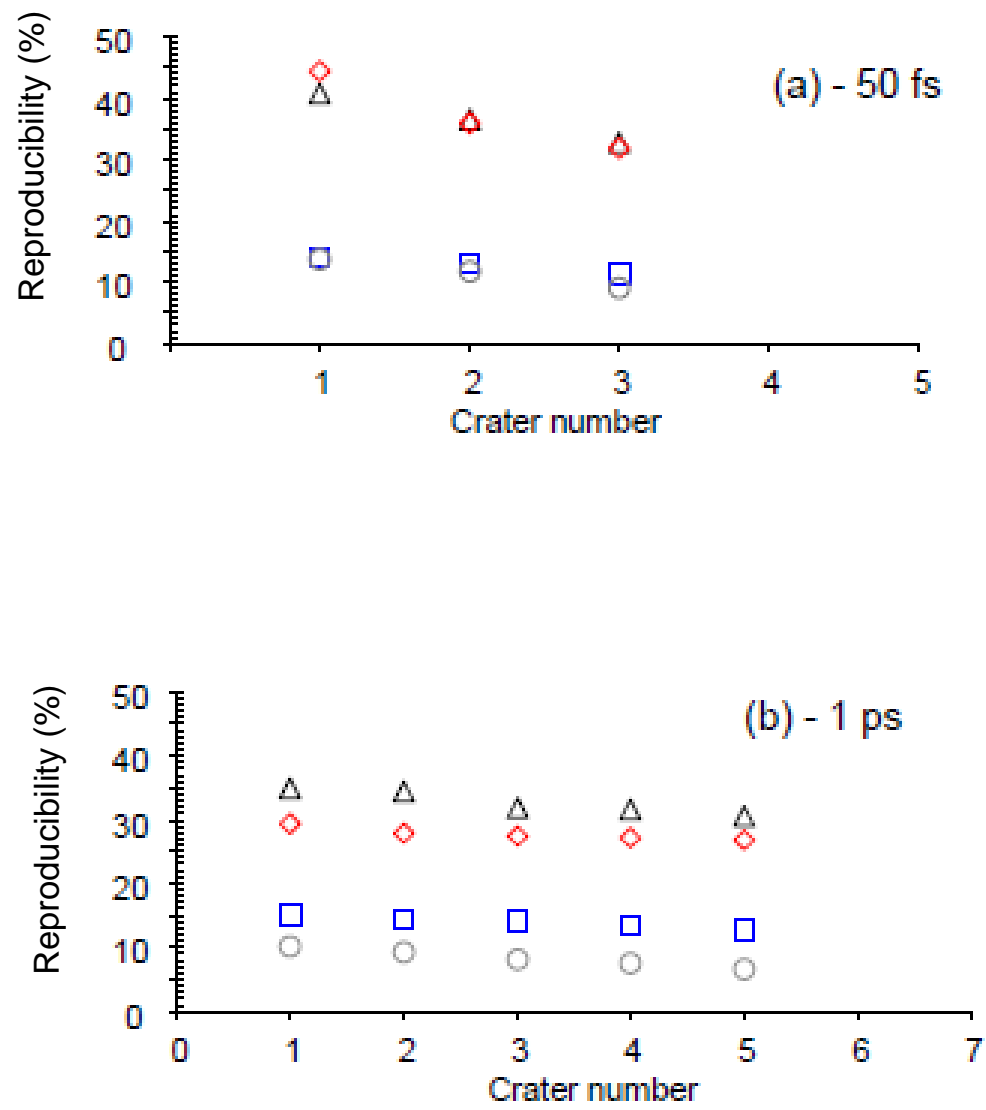

Figure 5. Al spectral line $(\lambda=396.15 \mathrm{~nm})$ intensity reproducibility $(\%)$ versus the surface crater number for the polished Al sample under ultrashort microablation $(40 \mu \mathrm{J}$, single and double pulses, in air and with Ar-jet, 30 shots per crater) with: (a) - $50 \mathrm{fs}$; (b) - 1 ps. $\Delta$ - single pulse in air, $\diamond$ - single pulse with Ar-jet, $\square$ - double pulses in air, $\bigcirc$ - double pulses with Ar-jet. For the sake of clarity, the data on reproducibility are presented in decreasing order.

The effect of double pulses on the improvement in the signal reproducibility has been demonstrated with the $\mathrm{Al}$ matrix sample with $\mathrm{Mg}$ mass content of 2.4\% (Mg-2 sample from Table 2). Thirty $\mathrm{Mg}$ spectra $(\lambda=516.732 \mathrm{~nm}, 517.268 \mathrm{~nm}, 518.36 \mathrm{~nm})$ obtained with single and double pulses (50 fs, $40 \mu \mathrm{J}$ per pulse, in air, 30 pulses per crater) are shown in Figures 6a and 6b, respectively. With double pulses, the signal reproducibility was also much better than the one obtained with a single pulse. 

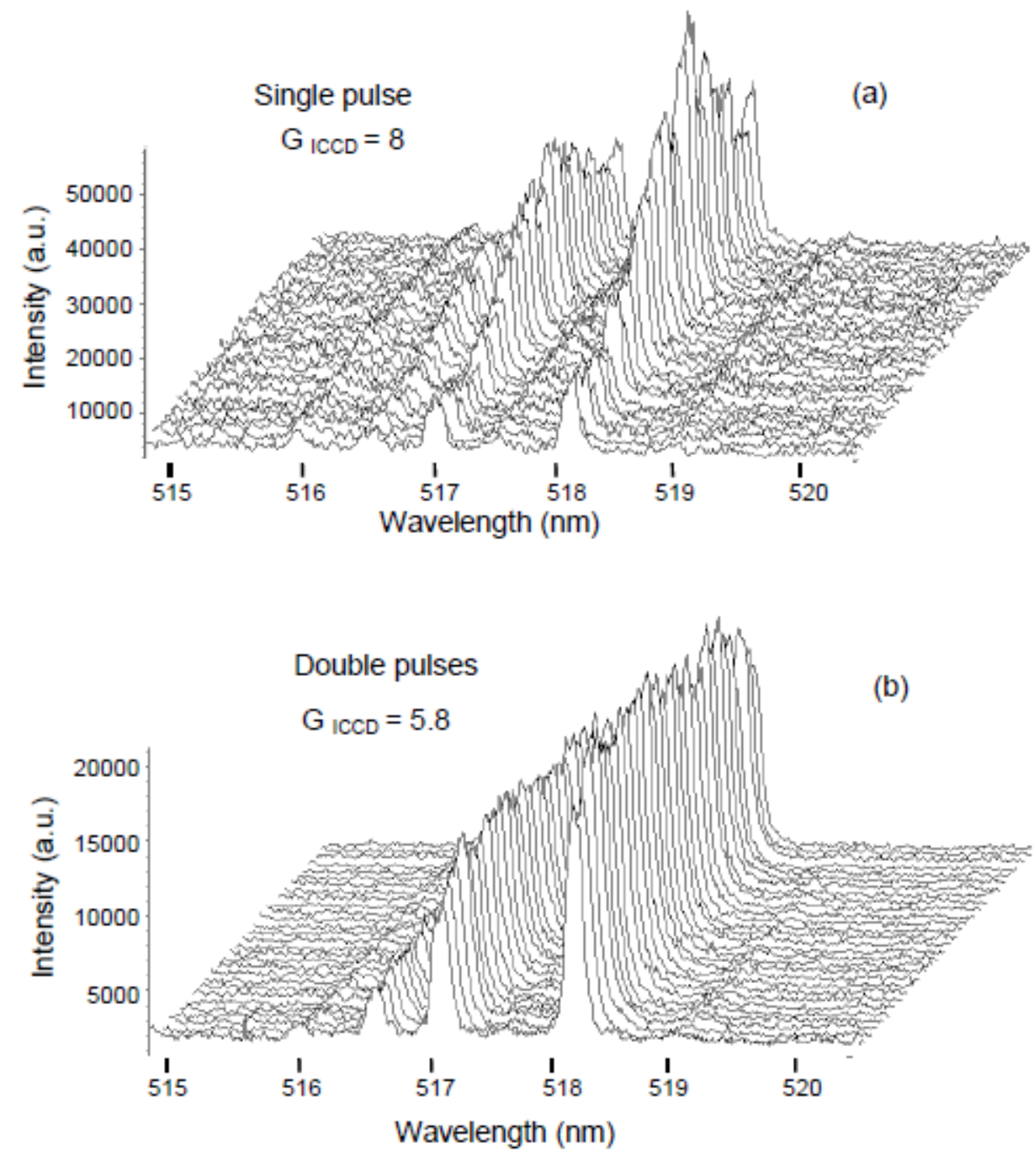

Figure 6. Thirty $\mathrm{Mg}$ spectra $(\lambda=516.73 \mathrm{~nm}, \lambda=517.26 \mathrm{~nm}, \lambda=518.36 \mathrm{~nm})$ of Al matrix sample with $\mathrm{Mg}$ content (2.4\%) under 50 fs microablation (40 $\mu \mathrm{J}, 30$ shots per crater): (a) - single pulse in air; (b) - double pulses in air. Mg spectral line width (FWHM) is $0.17 \mathrm{~nm}(\lambda=518.36 \mathrm{~nm})$, spectrometer resolution is $0.13 \mathrm{~nm}$ for $300 \mu \mathrm{m}$ entrance slit width, ICCD camera delay $t_{d}=150$ ns and gate width $t_{g}=2 \mu \mathrm{s}$. $\mathrm{G}_{\mathrm{ICCD}}$ - the applied ICCD camera gain.

The reproducibility of the signal intensity was affected by laser energy fluctuations. The increase in laser pulse energy fluctuations resulted in a reproducibility decrease of the spectral line. Figure 7 demonstrates the intensity reproducibility $(\%)$ of the Al spectral line $(\lambda=396.15$ $\mathrm{nm}$ ) for a laser beam with $4 \%$ and $10 \%$ laser energy stability. Shot-to-shot spectral line reproducibility with double pulses (10\%) was comparable with the one obtained with ns single pulse LIBS [4]. 


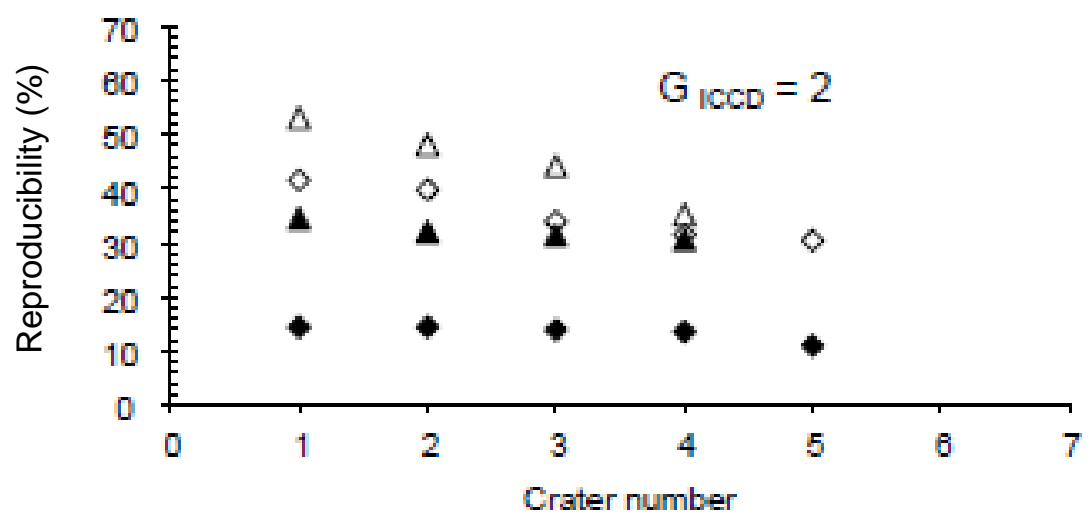

Figure 7. Al spectral line $(\lambda=396.15 \mathrm{~nm})$ intensity reproducibility $(\%)$ versus the surface crater number for the polished $\mathrm{Al}$ sample under $50 \mathrm{fs}$ microablation $(40 \mu \mathrm{J}$, single and double pulses, in air, 30 shots per crater) for $4 \%$ and $10 \%$ laser energy stability. $\Delta$ - single pulse, $10 \%$ laser energy stability; $\boldsymbol{\Delta}$ - double pulses, $10 \%$ laser energy stability; $\diamond$ - single pulse, $4 \%$ laser energy

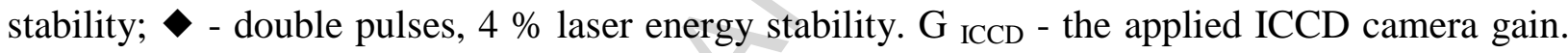
For the sake of clarity, the data on reproducibility are presented in decreasing order.

\subsection{Spectral line intensity gain}

To obtain and compare the intensity gain of the LIBS-signal under different experimental conditions, the polished Al sample was under microablation (50 fs, 1 ps, single and double pulses, in air and with Ar-jet) following a procedure similar to the one presented above for the reproducibility of the LIBS-signal (see Section 3.1.). The Al (396.4 nm) and $\mathrm{Mg}(518.36 \mathrm{~nm})$ spectral lines were registered by the ICCD camera as above (see section 3.1). The intensities of $\mathrm{Al}$ and $\mathrm{Mg}$ spectral lines obtained with 50 fs are shown in Figures $8 \mathbf{a}$ and $\mathbf{8 b}$, respectively. The spectral line gain was calculated for the maximum peak intensity and integrated peak area ("surface"” under spectral lines). The spectral background was subtracted in both cases. The Al and $\mathrm{Mg}$ spectral line gain calculated according to integrated peak area and maximum peak intensity for $50 \mathrm{fs}$ and $1 \mathrm{ps}$ under different experimental conditions are shown in Table 4. 

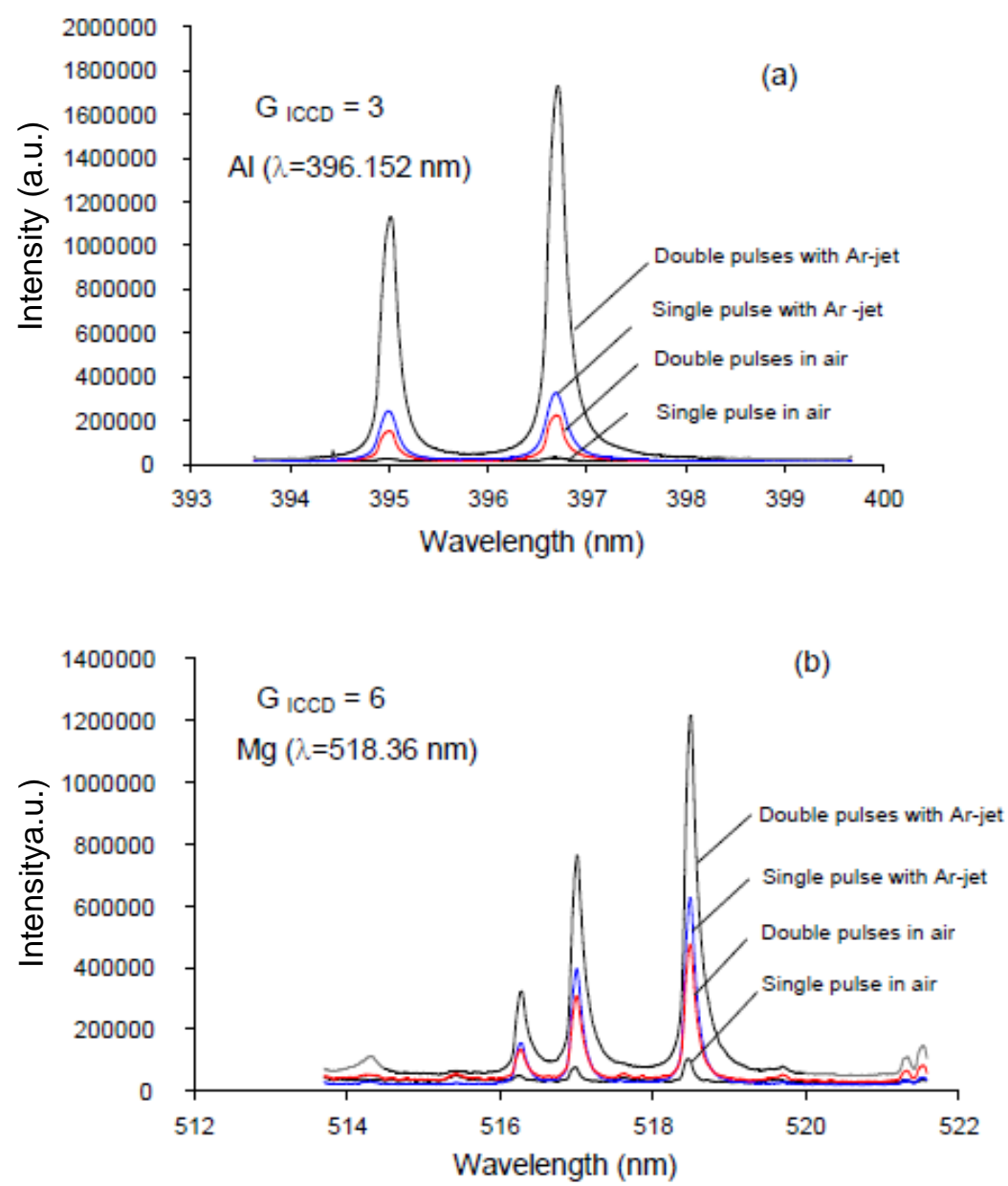

Figure 8. (a) - $\mathrm{Al}(\lambda=396.152 \mathrm{~nm})$ and (b) - $\mathrm{Mg}(\lambda=518.36 \mathrm{~nm})$ spectral line intensity for the polished $\mathrm{Al}$ matrix sample (with $\mathrm{Mg}$ of $1.5 \%$ mass content) under $50 \mathrm{fs}$ microablation (40 $\mu \mathrm{J}$, single and double pulses, in air and with Ar-jet). $\mathrm{G}_{\text {ICCD }}$ - the applied ICCD camera gain.

Table 4. Intensity gain for $\mathrm{Al}(\lambda=396.152 \mathrm{~nm})$ and $\mathrm{Mg}(\lambda=518.36 \mathrm{~nm})$ spectral lines calculated by intensity peak and "surface" for polished $\mathrm{Al}$ matrix sample under $50 \mathrm{fs}$ and 1 ps microablation $\left(40 \mu \mathrm{J}\right.$, single and double pulses, in air and with Ar-jet). $I_{1 \text { air }}$ and $\mathrm{I}_{1 \mathrm{Ar}}$ - intensity for single pulse in air and with Ar-jet, respectively. $\mathrm{I}_{2 \text { air }}$ and $\mathrm{I}_{2 \mathrm{Ar}}$ - intensity for double pulses in air and with Ar-jet, respectively.

\begin{tabular}{|c|c|c|c|c|c|c|c|}
\hline \multirow{2}{*}{ Element } & \multirow{2}{*}{$\tau$} & \multicolumn{2}{|c|}{$I_{\text {IAr }} / I_{\text {lair }}$} & \multicolumn{2}{|c|}{$I_{\text {2air }} / I_{\text {lair }}$} & \multicolumn{2}{c|}{$I_{2 A r} / I_{\text {lair }}$} \\
\cline { 3 - 7 } & & peak & "surface" & peak & "surface" & peak & "surface" \\
\hline \multirow{2}{*}{$\mathrm{Al}$} & $50 \mathrm{fs}$ & 8.5 & 9.8 & 4.3 & 4.5 & 26 & 32 \\
& $1 \mathrm{ps}$ & 7.8 & 9 & 4.1 & 4.8 & 28 & 37 \\
\hline $\mathrm{Mg}$ & $50 \mathrm{fs}$ & 9.7 & 8.3 & 7.5 & 6.8 & 19 & 14 \\
$(1.5 \%)$ & $1 \mathrm{ps}$ & 10 & 8.2 & 4.6 & 4.4 & 19 & 15 \\
\hline
\end{tabular}


The results obtained on the intensity gain of the spectral line in $\mathrm{Al}$ and $\mathrm{Mg}$ spectrum under the above experimental conditions may be summarized as follows:

- the intensity gain was almost the same for maximum peak intensities and integrated peak areas;

- the spectral line intensity gain was almost the same for both $50 \mathrm{fs}$ and 1 ps pulse durations;

- the highest intensity gain was with double pulses in Ar-jet;

- the intensity gain for Ar-jet with single pulses was higher than the one with double pulses in air.

\subsection{Calibration curves}

The calibration curves were obtained for $\mathrm{Al}$ matrix samples of the known $\mathrm{Mg}$ and $\mathrm{Cu}$ mass content (see Table 2). The procedure to obtain the calibration curve was the same for all the samples. The samples were under ultrashort microablation (50 fs/40 $\mu \mathrm{J}$ per pulse, $1 \mathrm{ps} / 40 \mu \mathrm{J}$ and $100 \mu \mathrm{J}$ per pulse, single and double pulses, 30 shots per crater, in air and with Ar-jet) to obtain 10 craters $(100 \mu \mathrm{m}$ apart on the target surface). The $\mathrm{Mg}$ and $\mathrm{Cu}$ spectral lines were registered by the ICCD camera to obtain a spectrum after each laser shot (Figure 6). Thirty spectra registered per crater were summed to obtain a single spectrum per crater. Then, the ratio of the analytical spectral line intensity to the one of the background was calculated. The mean value of these ratios for 10 craters was taken for each point of the calibration curve for each Al matrix sample. This procedure also allowed us to consider the surface inhomogeneity. For the Al matrix samples with the analytical element $(\mathrm{Cu}$ or $\mathrm{Mg}$ ) of a high mass content (above $10 \%$ ), the intensity of the spectroscopic signal was not stable and was changing from crater to crater. We suggested that this signal instability might be attributed to a non-homogeneous distribution of the impurities on a $10 \mu \mathrm{m}$ scale. As these samples were not suitable for calibration curve tracing, only the Al matrix samples with a lower $\mathrm{Cu}$ or $\mathrm{Mg}$ mass content (below 10\%) were used.

The ICCD camera gain $(\mathrm{G}=1-10)$ was the same for each calibration curve. The ICCD camera gain was chosen so as to avoid the saturation during the recording of the spectra corresponding to the highest $\mathrm{Mg}$ or $\mathrm{Cu}$ mass content.

The $\mathrm{Mg}$ calibration curves for the $\mathrm{Al}$ matrix samples with different $\mathrm{Mg}$ mass content (Table 2) obtained under femtosecond microablation (50 fs, $40 \mu \mathrm{J}$ per pulse, single pulses in air, double pulses in air, double pulses with Ar-jet) are shown in Figure 9. With a single pulse in air, it was necessary to use a high ICCD camera gain $(G=8)$, which testified to the fact that the analytical signal (spectral line intensity) was low. The reproducibility of the signal intensity was also low with a relative standard deviation (RSD) of around 30-40 \% (see Figure 6). As a result, the calibration curve was deteriorated, and its points were not well-aligned (Figure 9 a). With 
double pulses both in air and with Ar-jet, the points of the calibration curves were aligned quite well $(\mathrm{RSD}<15 \%)$. For double pulses with Ar-jet, it was possible to use a much lower ICCD camera gain $(\mathrm{G}=4.7)$, which testified to the important increase in the spectral line intensity (see Figure 9).
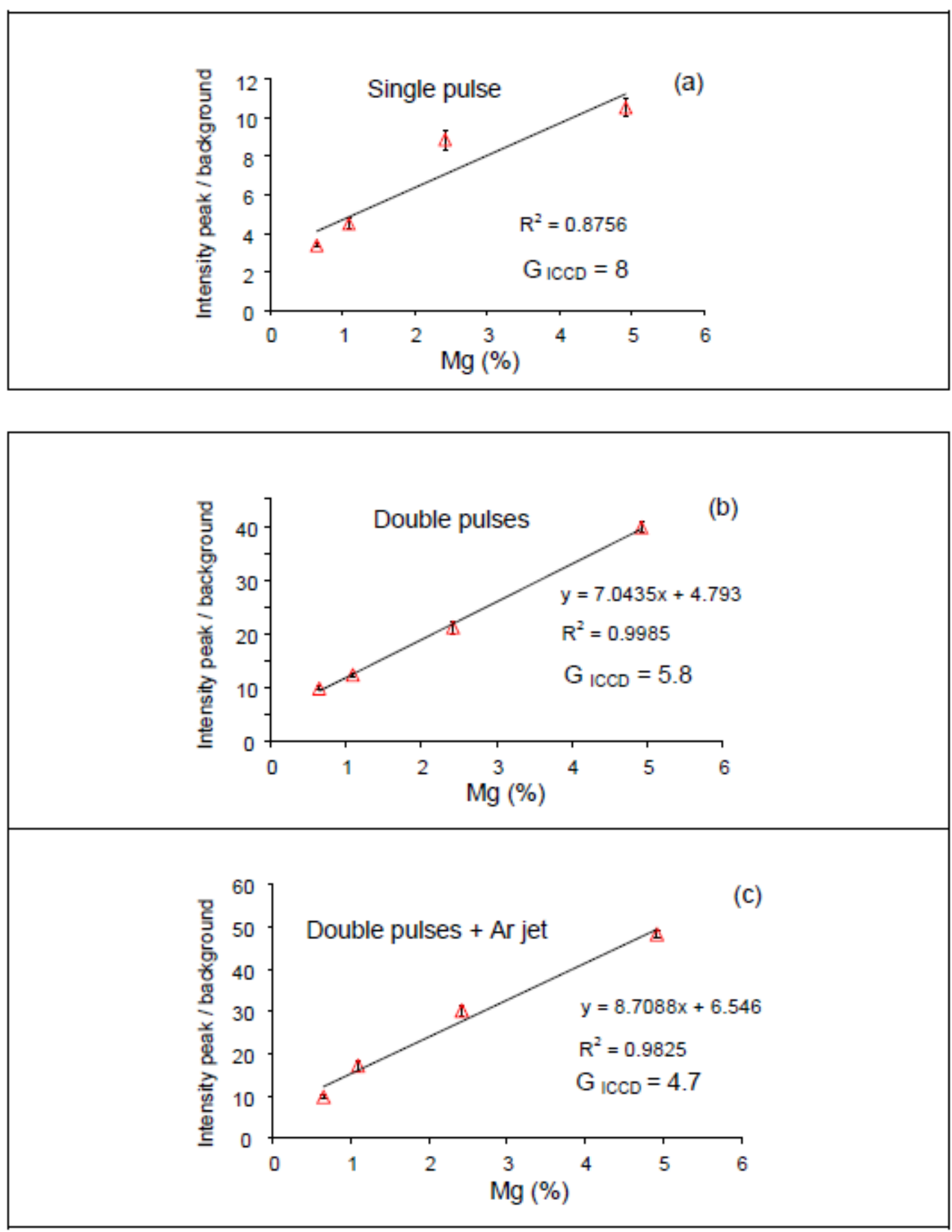

Figure 9. $\mathrm{Mg}$ calibration curves $(\lambda=518.36 \mathrm{~nm})$ for $\mathrm{Al}$ matrix samples with different $\mathrm{Mg}$ mass content $(4.9 \%, 2.4 \%, 1.1 \%, 0.65 \%)$ under 50 fs microablation $(40 \mu \mathrm{J}, 30$ shots per crater): (a) single pulse in air; (b) - double pulses in air, (c) - double pulses with Ar-jet. G ICCD - the applied ICCD camera gain. 
The $\mathrm{Cu}$ calibration curves were obtained by microablation of all four $\mathrm{Al}-\mathrm{Cu}$ samples (see Table 2) with 50 ps pulses (40 $\mu \mathrm{J}$ per pulse, double pulses, in air and with Ar-jet), while 1 ps microablation (with the same experimental parameters and conditions) was applied only for two of the samples (with $0.89 \%$ and $4.3 \% \mathrm{Cu}$ concentrations). The $\mathrm{Cu}$ calibration curves were almost similar and with well aligned points for both $50 \mathrm{fs}$ and $1 \mathrm{ps}$ double pulses in air and with Ar-jet (Figures 10a and 10b, respectively).

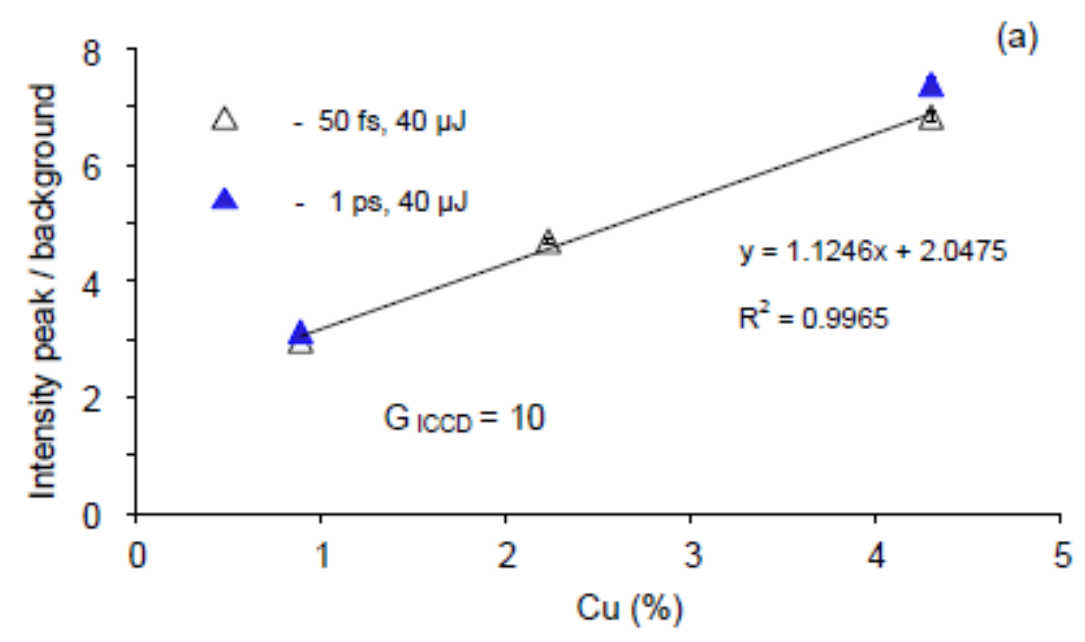

(b)

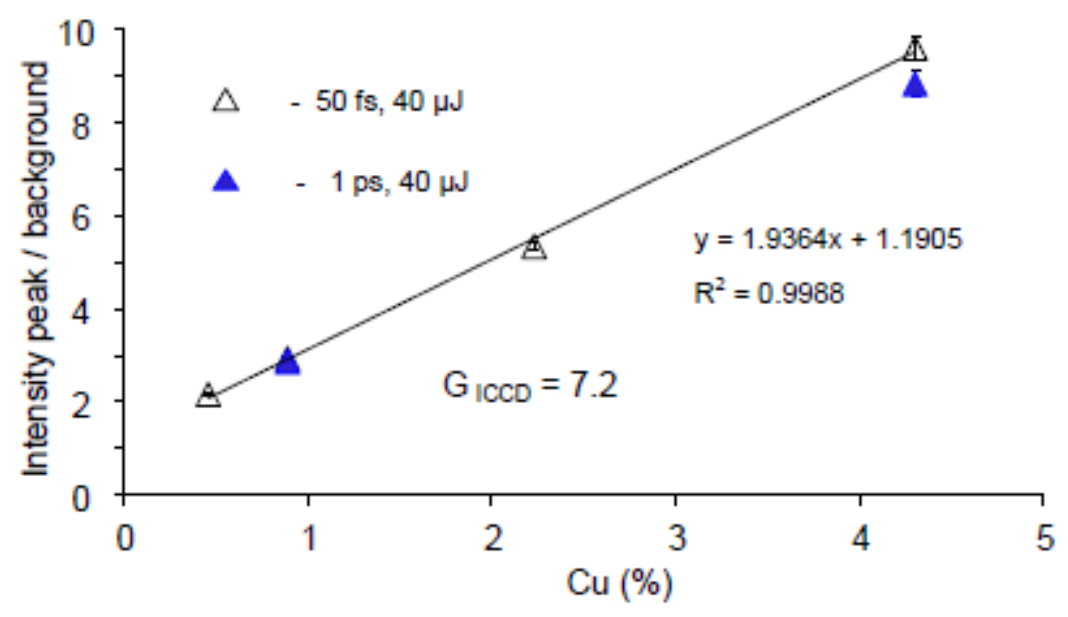

Figure 10. $\mathrm{Cu}$ calibration curves $(\lambda=521.82 \mathrm{~nm})$ for $\mathrm{Al}$ matrix samples with different $\mathrm{Cu}$ mass content $(4.3 \%, 2.2 \%, 0.9 \%$ and $0.46 \%)$ under 50 fs and 1 ps microablation $(40 \mu \mathrm{J}, 30$ shots per crater): (a) - double pulses in air; (b) - double pulses with Ar-jet. $\Delta-50$ fs; $\boldsymbol{\Delta}-1$ ps. G ICCD $_{\text {- }}$ the applied ICCD camera gain. 


\section{Discussion and conclusions}

\subsection{Micro-LIBS signal reproducibility}

In our study, the plasma size from the point of view of micro-LIBS signal reproducibility was under special attention. Magnification on the optical fiber entrance (Figure 2) was set so that the largest plasma sizes produced under our experimental conditions were inferior to the fiber core diameter. Thus, the effect of possible plasma shape variations on the signal reproducibility was reduced.

In all our experiments to observe the $\mathrm{Al}$ and $\mathrm{Mg}$ spectral lines, the reproducibility with double pulses was always better than the one with single pulses.

Reproducibility measurements were made with single pulses both in air and with Ar-jet. Ar-jet application did not result in any improvements in the signal reproducibility, but the spectral line intensities were observed to be increasing. As the Ar-jet has not improved the signal reproducibility, one may conclude that the improvements in reproducibility may be attributed to the application of double pulses.

\subsection{Analytical signal intensity}

The previous experiments have demonstrated that the following: (1) the plasma light was more intense with double pulses than with single pulses; (2) the plasma light intensity was slowly increasing with the increase in the interpulse delay $\Delta \mathrm{t}_{12}>10 \mathrm{ps}[\mathbf{1 6}]$. The observed $\mathrm{Al}, \mathrm{Cu}$ and $\mathrm{Mg}$ spectral lines were following the same pattern. With double pulses, the registered spectral lines were systematically more intense than those registered with single pulses (see Figure 8). With double pulses, the electronic temperature and density, and also the plasma lifetime were increasing [20]. It was suggested that the second pulse does not reach the target, but rather reheats the plasma by increasing its electronic density and temperature [38], and degree of atomization [19].

With Ar-jet application, we observed the intensity lines increase irrespective of all other experimental conditions. The effect of different buffer gases on iron lines was demonstrated in [39]. With Ar-jet, the plasma temperature and density were higher than those obtained in air. It should be also mentioned that some elements (Al, for example) are known to form oxides when the laser-induced plasma cools down and mixes with air. Thus, atomic species recombine with oxygen to form a molecule, thereby reducing the potential numbers of atomic emitters. An example of such molecular formation is presented in Figure 11. Thus, the use of an inert gas does not only result in the increase of the plasma's electronic temperature and density, but also reduces the effect of the oxidation of atomic species. 


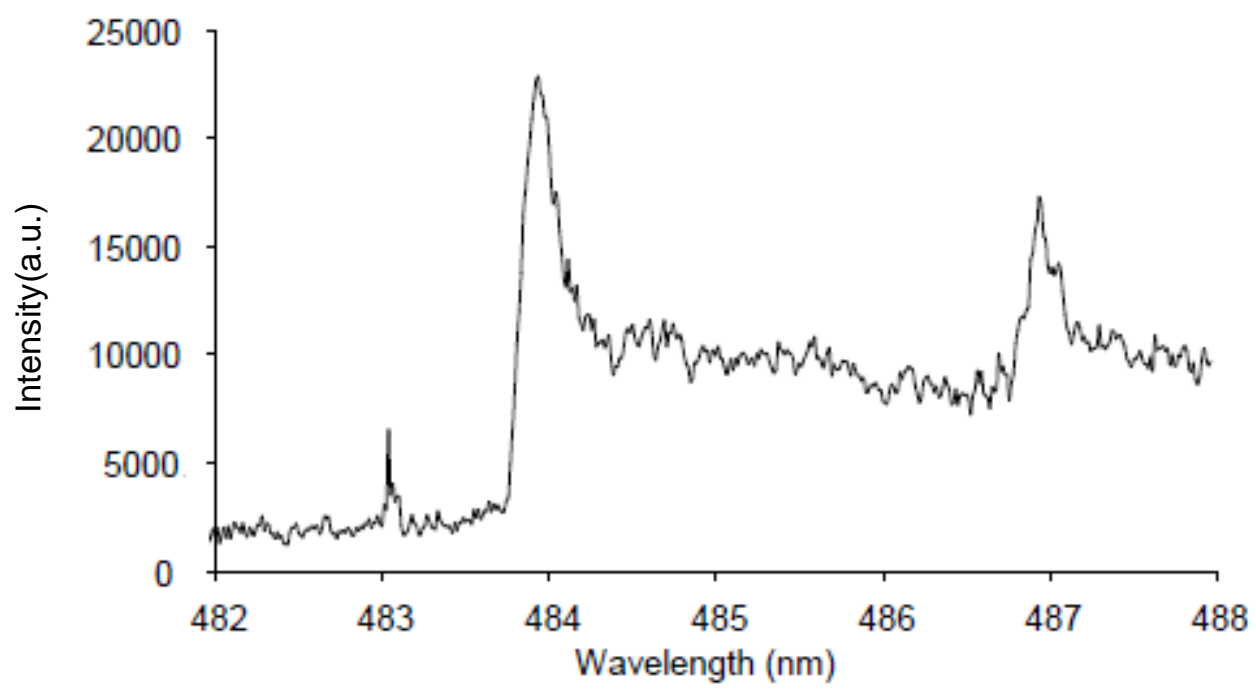

Figure 11. AlO spectrum for $\mathrm{Al}$ sample under $50 \mathrm{fs}$ microablation in air (40 $\mu \mathrm{J}$, single pulse).

From Table 4, one can see that the line intensity gain has been almost doubled with single pulses in Ar-jet if compared with the one obtained with double pulses in air.

\subsection{Calibration curves}

The $\mathrm{Cu}$ calibration curves obtained with $50 \mathrm{fs}$ and 1 ps pulse of the same energy $(40 \mu \mathrm{J})$ were found to superimpose quite well. This is in correlation with the results of our previous studies [17]. Crater volumes, depths and diameter were the same for metal samples irradiated by pulses with $50 \mathrm{fs}-1$ ps durations with identical experimental parameters [10-11]. In addition, the analysis of plasma images with 50 fs or 1 ps pulse durations has demonstrated that plasma reheating was identical in both the cases [16-17].

However, despite the above mentioned similar results obtained with 50 fs and 1 ps applications for microablation of Al-Cu samples in our study, there is an important difference in the use of these two pulse durations from the point of view of the laser pulse energy. Indeed, the maximum energy which may be used for $50 \mathrm{fs}$ pulses is actually much lower than that which may be applied for 1 ps pulses. With $50 \mathrm{fs}$ pulses, if the laser pulse energy is too high, one may observe undesirable non-linear effects that may significantly affect the focusing. Thus, the pulse energy should be limited for the pulses with durations in the range of a few tens of femtoseconds. In our study, with 50 fs pulses under the above experimental conditions, the maximum laser pulse energy was $40 \mu \mathrm{J}$.

For $1 \mathrm{ps}$ pulses, in contrast to $50 \mathrm{fs}$ pulses, these energy limits for a laser pulse are not imposed. Thus, a pulse of a higher energy may be used to increase mass removal and, as a result, plasma light emission. In our study with the polished Al sample, the intensity of the Al spectral 
line was assessed as a function of laser energy. The curve obtained for $2 \times 20-2 \times 200 \mu \mathrm{J}$ energies was linear (Figure 12). Thus, these results have demonstrated that it is far more advantageous to apply pulses with duration of a few ps rather than that of a few tens of fs.

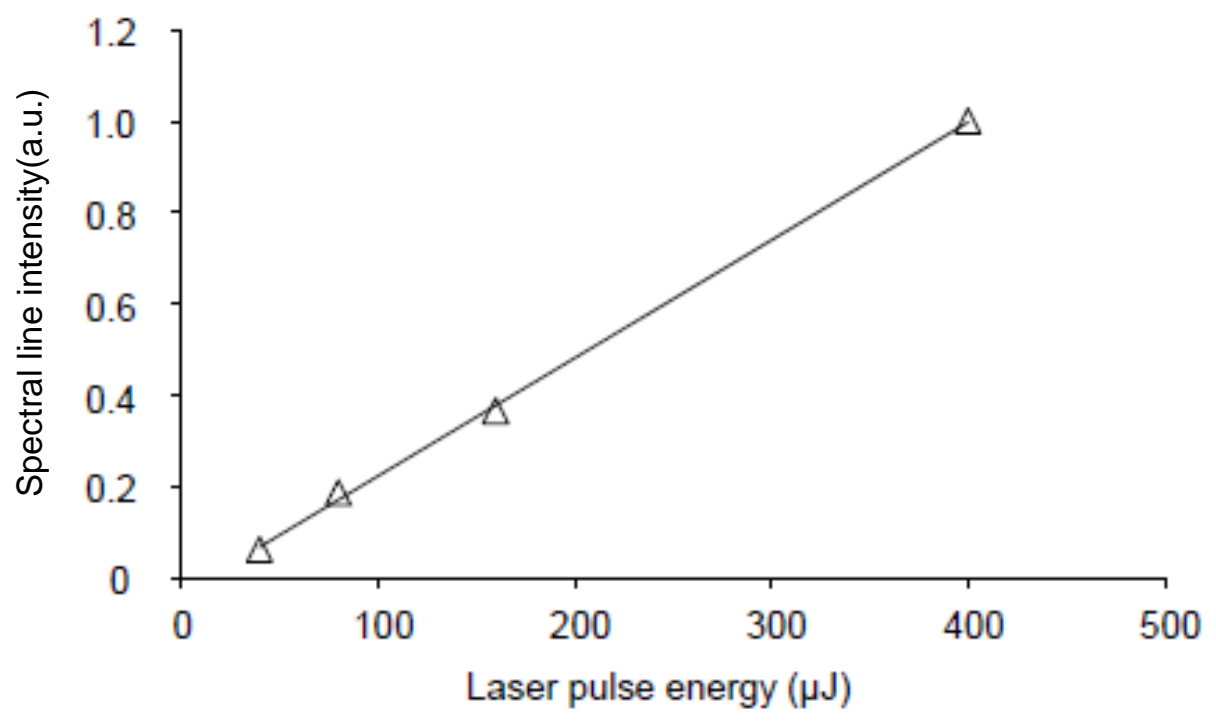

Figure 12. $\mathrm{Al}(\lambda=396.15 \mathrm{~nm})$ spectral line intensity (in arbitrary units) versus double pulse laser energy for $\mathrm{Al}$ matrix sample under 1 ps microablation (double pulses, in air).

Based on the above conclusions, new calibration curves were plotted with the $\mathrm{Al}-\mathrm{Mg}$ samples (see Table 2) for 1 ps pulses of a higher energy of $100 \mu \mathrm{J}$ with single pulses in air, with double pulses in air and with Ar-jet (Figure 13 a, b, c, respectively). These calibration curves demonstrate satisfactory correlation coefficients. The line intensities are indeed stronger than those obtained with $50 \mathrm{fs}$ pulses. In addition, the gain was set to a lower value than the one used with a $50 \mathrm{fs}$ pulse duration. From these results, one may conclude that there is no particular interest in applying 50 fs pulse durations for surface cartography by micro-LIBS. The reasons are as follows. Firstly, 50 fs duration pulses (if compared with $1 \mathrm{ps}$ ) have not demonstrated any advantages or improvements in lateral and depth resolutions when applied to surface cartography. Secondly, non-linear effects impose certain limits on the maximum usable energy and therefore plasma emission. Thus, all the reasons are in favour for the application of ps laser pulses for micro-LIBS surface cartography. 

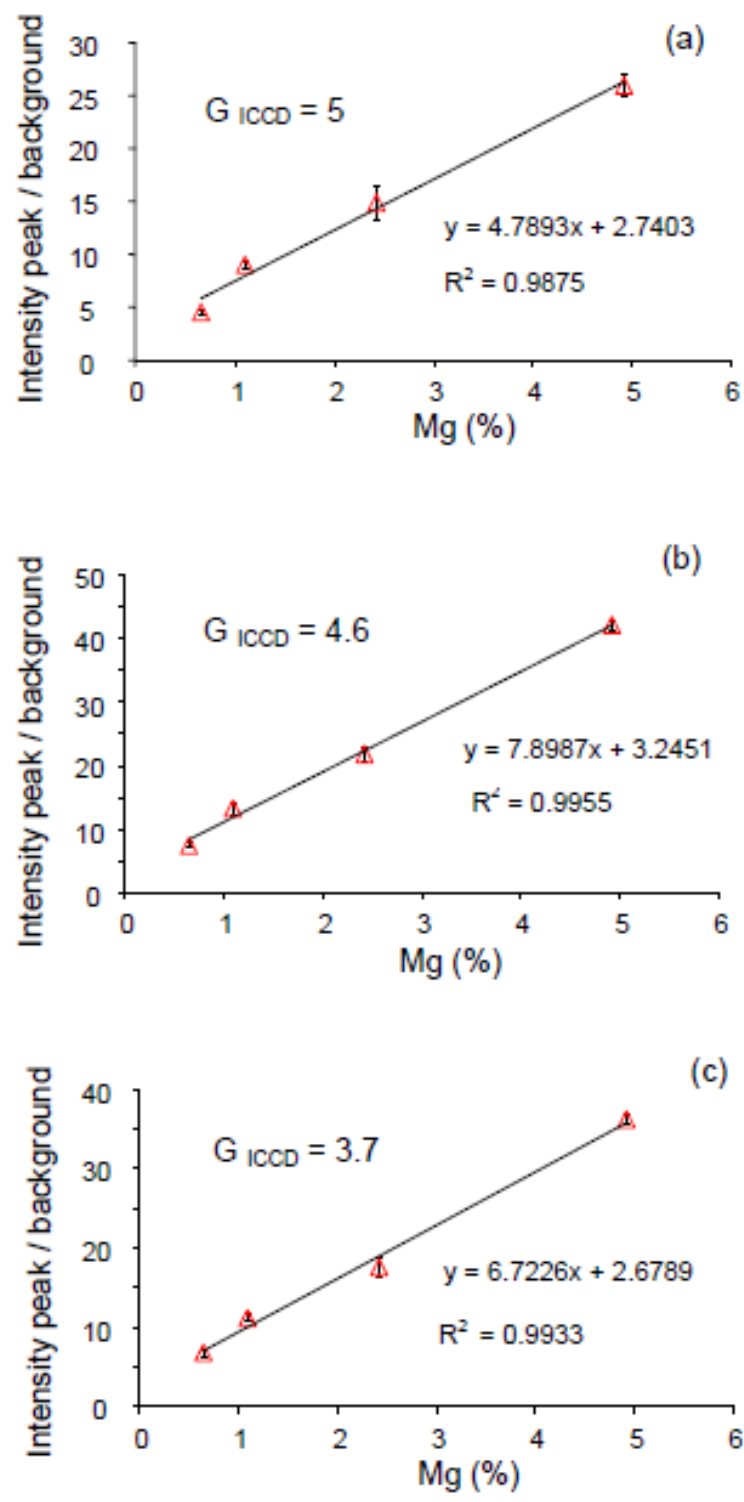

Figure 13. $\mathrm{Mg}$ calibration curve $(\lambda=518.36 \mathrm{~nm})$ for $\mathrm{Al}$ matrix samples with $\mathrm{Mg}$-concentrations $(4.9 \%, 2.4 \%, 1.1 \%, 0.65 \%)$ under 1 ps microablation $(100 \mu \mathrm{J}, 30$ shots per crater): (a) - single pulse in air; (b) - double pulses in air; (c) - double pulses with Ar-jet. $\mathrm{G}_{\mathrm{ICCD}}$ - the applied ICCD camera gain.

\subsection{Detection limits}

Based on the above conclusions which are in favour of the application of 1 ps pulses, the detection limit was inferred from the calibration curves obtained with 1 ps pulses. The calculation was made according to the procedure recommended by the International Union of Pure and Applied Chemistry (IUPAC)

$$
D L=\frac{3 \sigma}{s}
$$


where $\sigma$ - standard deviation and $s$ - calibration curve slope. The detection limit was evaluated with the $\mathrm{Mg}$ calibration curve obtained with a 1 ps microablation $(100 \mu \mathrm{J}$, double pulses, with Ar-jet, 30 pulses per crater), which provided the most important photon emission by the plasma plume (see Figure 13c). The standard deviation $\sigma$ and calibration curve slope $s$ were calculated over 5 x 30 accumulated spectra ( 5 craters, 30 laser shots per crater). An example of the accumulated spectrum after 30 laser shots is presented in Figure 14. The standard deviation was calculated for the $\mathrm{Al}$ matrix sample with the lowest $\mathrm{Mg}$ concentration $(0.65 \%)$ in our study. For $\mathrm{Mg}$, we obtained a DL of $0.0035 \%$, that is, $\mathrm{DL}=35 \mathrm{ppm}$.

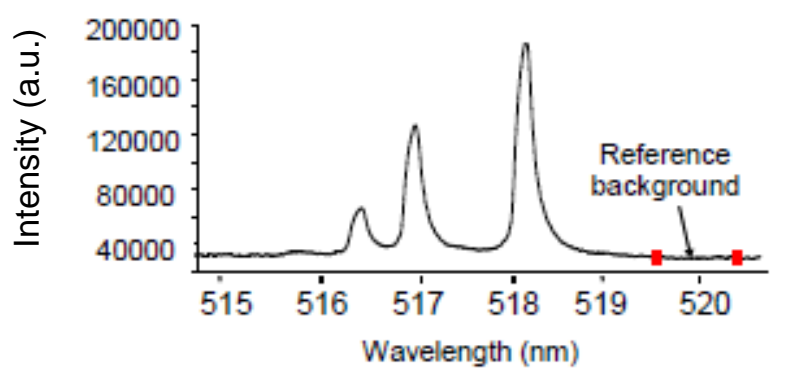

Figure 14. $\mathrm{Mg}$ spectrum (accumulated after 30 shots) for $\mathrm{Al}$ matrix sample with a low $\mathrm{Mg}$ concentration (0.65\%) under 1 ps microablation (100 $\mu \mathrm{J}$, double pulses, with Ar-jet). The standard deviation of the background intensity was calculated within the spectral zone indicated by two dots. The ICCD camera gain $\mathrm{G}_{\text {ICCD }}=3.7$.

The obtained results may be regarded as very promising for the following reasons. Firstly, the ICCD gain used for plotting the calibration curve was rather low (3.7/10). This means that the samples of lower concentrations could be under analysis with a higher ICCD gain. Secondly, the energy of the laser pulses may be increased to up to 2 x200 $\mu \mathrm{J}$ (the highest energy possible with our laser) with the optimized adjustments. Based on these considerations, one may expect the possibility to make concentration measurements in the $1-10 \mathrm{ppm}$ range.

\subsection{Conclusions}

The LIBS analytical signal is a complex feature which is determined by a number of properties (laser energy, laser pulse duration, time delay between consecutive laser shots, environment, target surface, transition probability and energy levels, ICCD-camera delay time and gate width for signal registration, plasma plume shape, etc.). The analytical signal is regarded as a peak intensity (or an integral intensity) of the detected spectral lines. To obtain a 
higher reproducibility of the analytical signal, we used the ratio of the spectral line intensity of the analytical element versus the background intensity. The efficiency of Al sample ablation with $50 \mathrm{fs}-1 \mathrm{ps}$ pulses does not depend on the laser pulse duration $[\mathbf{1 0 - 1 1 , 1 3}$. For $50 \mathrm{fs}$ pulses, the maximum pulse energy did not exceed $40 \mu \mathrm{J}$ so that the undesirable nonlinear effects inherent to fs laser propagation in air ( $10 \mu \mathrm{m}$ waist spot) may be avoided.

$\mathrm{Al}$ matrix samples with $\mathrm{Mg}$ and $\mathrm{Cu}$ analytical elements of different concentrations have been subjected to microablation (50 fs and 1 ps, single and double pulses, in air and with Ar-jet) to obtain several micro-LIBS analytical features (reproducibility, line intensity gain, calibration curves and detection limits).

The obtained micro-LIBS signal features were compared. The micro-LIBS signal reproducibility was better with double pulses than the one with single pulses, irrespective of pulse duration (50 fs or $1 \mathrm{ps}$ ) and environment (in air or with Ar-jet). RSD values were ranging from $10-15 \%$ for $50 \mathrm{fs}$ pulses, and $7-10 \%$ for 1 ps pulses. The line intensity gain was defined by the ratio of the line intensity obtained with: 1) double pulses in air, 2) single pulses in Ar-jet, and 3) double pulses in Ar-jet versus the line intensity which was recorded with single pulses in air. For the above three cases, the line intensity gain was around 5, 10 and 20, respectively.

The calibration curves were plotted for $\mathrm{Al}-\mathrm{Mg}$ and $\mathrm{Al}-\mathrm{Cu}$ samples, with $\mathrm{Mg}$ and $\mathrm{Cu}$ concentrations in a few tens of ppm range. The calibration curves obtained with $50 \mathrm{fs}$ and $1 \mathrm{ps}$ pulse durations were found to superimpose quite well. For both $50 \mathrm{fs}$ and $1 \mathrm{ps}$, the lateral and depth resolutions and plasma light emission were similar. However, with 50 fs laser pulses, the maximum accessible pulse energy should not be too high so as to avoid undesirable nonlinear effects in air. With 50 fs pulses under our experimental conditions, the maximum laser energy was $40 \mu \mathrm{J}$, while with 1 ps pulses it was possible to use a higher laser pulse energy (200 $\mu \mathrm{J}$ in our study). Thus, to determine the detection limits of the analytical element of the samples under study, the application of 1 ps pulses with the increased pulse energy was considered as more advantageous. A 1 ps laser pulse of $100 \mu \mathrm{J}$ energy was used to obtain the calibration curve to determine the detection limit of $\mathrm{Mg}$ in the Al-Mg samples under study. The detection limit was around $35 \mathrm{ppm}$.

For both 50 fs and 1 ps pulses under the experimental conditions of this study, the ablation and plasma properties were almost the same. However, taken into account the limited pulse energy for 50 fs pulses, one may conclude that 1 ps pulses should be regarded as more advantageous and quite promising for LIBS micro-analysis in air in the ppm concentration range. Further investigations are required to study higher laser energies and ICCD gains, which could yield satisfying results in the ppm concentration range. 
The analysis of our results and those obtained in [19-36] has revealed the fundamental role of the electron-lattice relaxation time $\left(\tau_{\mathrm{el}} . \approx 1-10 \mathrm{ps}\right)$ for laser ablation regime and the resulting double pulse LIBS-features. At $t<\tau_{\mathrm{el}}$, the energy of the first laser pulse is absorbed by the conduction band electrons in metal, thus causing a rapid increase in the temperature of electrons. At $t \approx \tau_{\mathrm{el}}$ when the electron-lattice relaxation takes place, the lattice temperature and pressure are increasing and result in matter ablation, followed by laser plasma formation at $\mathrm{t}>$ $\tau_{\mathrm{el}}$. Thus, for the LIBS-method with double pulses, the delay between laser pulses $\Delta \mathrm{t}_{12}$ may be considered as a determining feature for the interaction regime. At $\Delta \mathrm{t}_{12}<\tau_{\mathrm{el}}$, the crater depth is increased for each applied pulse. That is, for both single and double pulses of the same energy, the ablation rate is the same [17] and does not depend on the pulse duration [13]. For $\Delta \mathrm{t}_{12}>\tau_{\mathrm{el}}$ $\left(\Delta \mathrm{t}_{12} \approx 10 \mathrm{ps}\right.$, in our case), the second pulse reheats the ablated matter without causing any additional ablation. In this case, the second delayed pulse results in the increase in the atomization and excitation degree of the plasma plume, thus improving the LIBS-performances with ultrashort pulses. One should mention that the data of the double pulse ablation modeling in [35-36] are in correlation with the experimental results, thus confirming our adequate understanding of the mechanisms of ultrashort double pulse laser ablation.

\section{Acknowledgements.}

We are grateful to our colleagues: Dr. Olivier Gobert, Mr. Pierre Meynadier, and Mr. Michel Perdrix for their assistance in our experimental study. 


\section{References.}

[1] C. Geertsen, J.L. Lacour, P. Mauchien, L. Pierrard, Evaluation of laser ablation optical emission spectrometry for microanalysis in aluminium samples, Spectrochim. Acta Part B 51 (1996) 1403-1416.

[2] V. Detalle, J.L. Lacour, P. Mauchien, A. Semerok, Investigation of laser plasma for solid element composition microanalysis, Appl. Surf. Sci. 138 (1999) 299-301.

[3] G.W. Rieger, M. Taschuk, Y.Y. Tsui, R. Fedosejevs, Laser-induced breakdown spectroscopy for microanalysis using submillijoule UV laser pulses, Appl. Spectrosc. 56 (2002) 689-698.

[4] D. Menut, P. Fichet, J.L. Lacour, A. Rivoallan, and P.Mauchien, Micro-laser-induced breakdown spectroscopy technique: a powerful method for performing quantitative surface mapping on conductive and nonconductive samples, Appl. Optics 42 (2003) 6063-6071.

[5] I. Gornushkin, B. Smith, N. Omenetto, J. Winefordner, Microchip laser induced breakdown spectroscopy: a preliminary feasibility investigation, Appl. Spectrosc. 58 (2004) 762-769.

[6] M. Taschuk, I. Cravetchi, Y. Tsui, R. Fedosejevs, Micro-libs, in: J.P. Singh, S.N. Thakur (Eds.), Laser-Induced Breakdown Spectroscopy, Elsevier, Amsterdam (2007), pp. 173-196.

[7] X. Wang, V. Motto-Ros, G. Panczer, D. De Ligny, J. Yu, J.M. Benoit, J.L. Dussossoy, S. Peuget, Mapping of rare earth elements in nuclear waste glass-ceramic using micro laserinduced breakdown spectroscopy, Spectrochim. Acta Part B 87 (2013) 139-146.

[8] A. Semerok, C. Chaleard,V. Detalle, S. Kocon, J.L. Lacour, P. Mauchien, P. Meynadier, C. Nouvellon, P. Palianov, M. Perdrix, G. Petite, B. Salle, Laser ablation efficiency of pure metals with femtosecond, picosecond and nanosecond pulses, Proceedings of SPIE 3343 (1998) 10491055.

[9] B. Sallé, Etude de l'interaction laser - matériau appliquée à l'analyse élémentaire des solides (PhD thesis) Université d'Orléans (1999) France.

[10] B. Sallé, O. Gobert, P. Meynadier, M. Perdrix, G. Petite and A. Semerok, Femtosecond and picosecond laser microablation: ablation efficiency and laser microplasma expansion, Appl. Phys. A69 (1999) S381-S383. 
[11] A. Semerok, B. Sallé, J.-F. Wagner, G. Petite, O. Gobert, P. Meynadier and M. Perdrix, Microablation of pure metals: Laser plasma and crater investigations, Proceedings of SPIE 4423 (2001) 153-164.

[12] M. Hashida, A. Semerok, O. Gobert, G. Petite, J.F. Wagner, Ablation thresholds of metals with femtosecond laser pulses, 10th International Conference on Nonresonant Laser-Matter Interaction, St. Petersburg, Russia, 21-23 august, 2000, Proceedings of SPIE 4423 (2001) 178185.

[13] A. Semerok, B. Salle, J.F. Wagner, Femtosecond, picosecond, and nanosecond laser microablation: Laser plasma and crater investigation, Laser Part. Beams 20 (2002) 67-72.

[14] M. Hashida, M. Fujita, M. Tsukamoto, A. Semerok, O. Gobert, G. Petite, Y. Izawa, J.F. Wagner, Femtosecond laser ablation of metals: Precise measurement and analytical model for crater profiles, 3rd International Symposium on Laser Precision Microfabrication, OSAKA, JAPAN, May 27-31, 2002, Proceedings of SPIE 4830 (2003) 452-457.

[15] S.I. Anisimov, B. Rethfeld, On the theory of ultrashort laser pulse interaction with a metal, 9th International Conference on Nonresonant Laser-Matter Interaction, St. Petersburg, Russia, 01-03 July 1996, Proceedings of SPIE 3093 (1997) 192-203.

[16] A. Semerok, C. Dutouquet, Ultrashort double pulse laser ablation of metals, Thin Solid Films 453-454 (2004) 501-505.

[17] C. Dutouquet, A. Semerok, Etudes préliminaires des performances analytiques lors de l'ablation avec des impulsions femtosecondes, CEA report, NT DPC/SCP/LILM/04-098-A (2004) 1-61.

[18] A. Semerok, P. Mauchien, Ultrashort pulse laser ablation for surface elemental analysis, The Review of Laser Engineering 33 (2005) 530-536.

[19] D. Scuderi, O. Albert, D. Moreau, P. P. Pronko, and J. Etchepare, Interaction of a laserproduced plume with a second time delayed femtosecond pulse, Appl. Phys. Lett. 86 (2005) 071502 .

[20] V. Piñon, C. Fotakis, G. Nicolas, D. Anglos, Double pulse laser-induced breakdown spectroscopy with femtosecond laser pulses, Spectrochim. Acta Part B 63 (2008) 1006-1010.

[21] V. Pinon, D. Anglos, Optical emission studies of plasma induced by single and double femtosecond laser pulses, Spectrochim. Acta B 64 (2009) 950-960. 
[22] S. Noel, E. Axente, J. Hermann, Investigation of plumes produced by material ablation with two time-delayed femtosecond laser pulses, Appl. Surf. Sci. 255 (2009) 9738-9741.

[23] S. Noel and J. Hermann, Reducing nanoparticles in metal ablation plumes produced by two delayed short laser pulses, Appl. Phys. Lett. 94 (2009) 053120.

[24] J Hermann, L Mercadier, E Axente, S Noël, Properties of plasmas produced by short double pulse laser ablation of metals, Journal of Physics: Conference Series 399 (2012) 012006

[25] S. Amorouso, X. Wang, C. Altucci, C. de Lisio, M. Armenante, R. Bruzzese, and R. Velotta, Appl. Phys. Lett. 77 (2000) 3728.

[26] X. Wang, S. Amoruso, J. Xia, Temporally and spectrally resolved analysis of a copper plasma plume produced by ultrafast laser ablation, Appl. Surf. Sci. 255 (2009) 5211-5214.

[27] T. Donnelly, J. G. Lunney, S. Amoruso, R. Bruzzese, X. Wang, and X. Ni, Double pulse ultrafast laser ablation of nickel in vacuum, J. Appl. Phys. 106 (2009) 013304.

[28] S. Amoruso, R. Bruzzese, X. Wang, G. O’Connell, and J. G. Lunney, Multidiagnostic analysis of ultrafast laser ablation of metals with pulse pair irradiation, J. Appl. Phys. 108 (2010) 113302.

[29] X. Li, L. Jiang, and H.-L. Tsai, Phase change mechanisms during femtosecond laser pulse train ablationof nickel thin films, J. Appl. Phys. 106 (2009) 064906.

[30] D.E. Roberts, A. du Plessis, L.R. Botha, Femtosecond laser ablation of silver foil with single and double pulses, Appl. Surf. Sci. 256 (2010) 1784-1792.

[31] V.I. Babushok, F.C. DeLucia Jr., J.L. Gottfried, C.A. Munson, A.W. Miziolek, Double pulse laser ablation and plasma: Laser induced breakdown spectroscopy signal enhancement, Spectrochim. Acta Part B 61 (2006) 999-1014.

[32] J. P. Colombier, P. Combis, A. Rosenfeld, I. V. Hertel, E. Audouard, and R. Stoian, Optimized energy coupling at ultrafast laser-irradiated metal surfaces by tailoring intensity envelopes: Consequences for material removal from Al samples, Phys. Rev. B 74 (2006) 224106.

[33] M. Guillermin, J. P. Colombier, S. Valette, E. Audouard, F. Garrelie, and R. Stoian, Optical emission and nanoparticle generation in Al plasmas using ultrashort laser pulses temporally optimized by real-time spectroscopic feedback, Phys. Rev. B 82 (2010) 035430. 
[34] J.P. Colombier, E. Audouard, R. Stoian, Laser pulses designed in time by adaptive hydrodynamic modeling for optimizing ultra-fast laser-metal interactions, Appl. Phys. A 110 (2013) 723-729.

[35] M. E. Povarnitsyn, T. E. Itina, K. V. Khishchenko, and P. R. Levashov, Suppression of Ablation in Femtosecond Double-Pulse Experiments, Phys. Rev. Lett. 103 (2009) 195002.

[36] M. E. Povarnitsyn, T. E. Itina, P. R. Levashov, K. V. Khishchenko, Simulation of ultrashort double-pulse laser ablation, Appl. Surf. Sci. 257 (2011) 5168-5171.

[37] NIST WEB site: http://physics.nist.gov/PhysRefData/ASD/lines_form.html

[38] K.L. Eland, D.N. Stratis, D.M. Gold, S.R. Goode and S.M. Angel, Appl. Spectrosc. 55 (3) 2001 p 286

[39] J.A. Aguilera, C. Aragon, A comparison of the temperatures and electron densities of laserproduced plasmas obtained in air, argon, and helium at atmospheric pressure, Appl. Phys. A 69 (1999) 475-478. 


\section{Highlights}

- Micro-LIBS analytical performances (reproducibility, line intensity gain, calibration curves and detection limits) were studied with ultrashort laser pulses (50 fs and 1 ps, single and double pulses, in air and with Ar-jet).

- The line intensity gain was obtained with double pulses in air, single pulses in Ar-jet, and double pulses in Ar-jet versus the line intensity which was recorded with single pulses in air. For the above three cases, the line intensity gain was around 5, 10 and 20, respectively.

- For both 50 fs and 1 ps pulses under the experimental conditions of this study, the ablation and plasma properties were almost the same.

- Calibration curves were plotted for Al-Mg and $\mathrm{Al}-\mathrm{Cu}$ samples with $\mathrm{Mg}$ and $\mathrm{Cu}$ concentrations in a few tens of ppm range. The detection limit was around $35 \mathrm{ppm}$. 